\title{
Using Cone Beam Computed Tomography Angle for Predicting the Outcome of Horizontal Bone Augmentation
}

\author{
Carlos Garaicoa, DDS;* Fernando Suarez, DDS; ${ }^{\dagger}$ Jia-Hui Fu, BDS, MS; ${ }^{\ddagger}$ Hsun-Liang Chan, DDS, MS; ${ }^{\$}$ \\ Alberto Monje, DDS; ${ }^{\Im}$ Pablo Galindo-Moreno, DDS, PhD;** Hom-Lay Wang, DDS, MS, PhD ${ }^{\dagger \dagger}$
}

\begin{abstract}
Background: The aim of this study was to assess the influence of ridge morphology on the amount of horizontal bone augmentation achieved with the sandwich bone augmentation (SBA) technique in the reconstruction of buccal dehiscence defects on dental implants.
\end{abstract}

Methods: Cone beam computed tomography (CBCT) was used to assess bone width changes in 26 patients who participated in a randomized controlled trial conducted in 2008 to 2011. The amount of horizontal bone gain was evaluated at four different levels $(3,6,9$, and $12 \mathrm{~mm}$ apical to the alveolar crest) and three different time points (T1: baseline, T2: at time of graft placement, and T3: 6 months later). Different morphological characteristics of the alveolar ridge were also evaluated to determine their influence on horizontal bone augmentation. A total of 78 CBCT scans were assessed.

Results: Comparison of the changes in ridge morphology at all measurement locations showed an overall ridge width gain of $2.30 \pm 2.20 \mathrm{~mm}$ after 6 months. The use of membranes and the angulation of the concavity played a role in influencing the outcomes of the SBA technique. Critical crest angulation (CA) is $150^{\circ}$ for bone gain at $9 \mathrm{~mm}$ apical to the crest. When $\mathrm{CA}$ is smaller than $150^{\circ}$, the horizontal bone gain was $4.3 \pm 2.2 \mathrm{~mm}$; if CA is greater than $150^{\circ}$, the gain was significantly lower at $1.3 \pm 1.7 \mathrm{~mm}(p=.001)$.

Conclusions: SBA is a reliable and predictable technique to gain horizontal ridge width with simultaneous implant placement. Crest ridge angulation can be used as a tool to predict bone gain at $9 \mathrm{~mm}$ apical to the bone crest.

KEY WORDS: alveolar ridge reconstruction, bone allograft, bone augmentation, cone beam CT, guided bone regeneration, implant

\begin{abstract}
${ }^{*}$ Visiting scholar, Graduate Periodontics, Department of Periodontics and Oral Medicine, University of Michigan School of Dentistry, Ann Arbor, MI, USA; ${ }^{\dagger}$ resident, Graduate Periodontics, Department of Periodontics and Oral Medicine, University of Michigan School of Dentistry, Ann Arbor, MI, USA; " assistant professor, Discipline of Periodontics, National University of Singapore, School of Dentistry, Singapore; '\$assistant professor, Graduate Periodontics, Department of Periodontics and Oral Medicine, University of Michigan School of Dentistry, Ann Arbor, MI, USA; 'resident, Graduate Periodontics, Department of Periodontics and Oral Medicine, University of Michigan School of Dentistry, Ann Arbor, MI, USA; ${ }^{* *}$ professor, Department of Oral Surgery and Implantology, University of Granada, Granada, Spain; ${ }^{\dagger \dagger}$ professor, Graduate Periodontics, Department of Periodontics and Oral Medicine, University of Michigan School of Dentistry, Ann Arbor, MI, USA
\end{abstract}

Reprint requests: Professor Hom-Lay Wang, Department of Periodontics and Oral Medicine, University of Michigan School of Dentistry, 1011 North University Avenue, Ann Arbor, MI 48109-1078. USA; e-mail: homlay@umich.edu

(C) 2013 Wiley Periodicals, Inc.

DOI 10.1111/cid.12174

\section{INTRODUCTION}

Ideally, the dental implant should be placed in a prosthetically driven position. However, with tooth extraction, there is an inevitable loss of alveolar ridge volume $e^{1,2}$ whereby the loss of horizontal ridge width occurs more frequently and to a greater extent compared with the loss of vertical ridge height $(\mathrm{RH}) .^{2}$ This commonly results in inadequate bone volume, thus preventing the implant from being placed in an ideal position. In order to overcome these deficiencies, bone augmentation procedures, such as guided bone regeneration (GBR), were used to regenerate the lost alveolar ridge ${ }^{3,4}$ prior to implant placement. This technique uses the concept for guided tissue regeneration ${ }^{5}$ to regenerate bone with the help of bone grafts and barrier membranes. ${ }^{6}$ It has been shown to be a predictable procedure with minimal complications. ${ }^{78}$ 
In recent years, the sandwich bone augmentation (SBA) technique was introduced through which GBR was done with simultaneous implant placement. ${ }^{9}$ This technique allows the clinician to maximize the treatment outcomes of GBR by utilizing the properties of various bone grafts. ${ }^{10}$ First, autogenous bone, because of its ability for de novo bone formation, is used to cover the exposed implant surfaces. Next, particulated cancellous bone allograft, mimicking cancellous bone in native bone, is placed over the autograft. Particulated cortical bone allograft is subsequently placed and this layer resembles the cortical bone layer in native bone. Lastly, a barrier membrane is used to protect the underlying bone graft and also to serve as a barrier to exclude undesirable nonregenerative cells such as the epithelial and gingival connective tissue cells. Having multiple layers of bone grafts over the exposed implant surface recreates the native bone composition, thus allowing for the reconstitution of lost bone around the implant. ${ }^{10}$ Previous studies have evaluated the effectiveness of the SBA technique for the correction of buccal dehiscences on implants. The authors have reported an increase in horizontal bone width by 1.2 to $1.7 \mathrm{~mm}$. In addition, the addition of a barrier membrane might prevent significant horizontal buccal bone resorption when compared with those treated without a membrane. ${ }^{11,12}$

It is known that good surgical technique is imperative to the success of bone augmentation procedures. ${ }^{13}$ This is because alterations in achieving primary wound closure, adequate angiogenesis, space creation, space maintenance, and wound stability, can lead to an increased risk of membrane exposure and subsequently microorganism colonization, thus diminishing the amount of bone regeneration that can occur. Other factors, such as ridge angle, have also been found to influence the amount of peri-implant bone regeneration. ${ }^{14}$ However, there is limited evidence evaluating the effect of ridge morphology on GBR. Therefore, this study aims to determine the influence of the alveolar ridge morphology on the success of SBA technique with simultaneous implant placement in increasing ridge width.

\section{MATERIALS AND METHODS}

This retrospective cone beam computed tomography (CBCT) study was approved by the University of Michigan Institutional Review Boards (ID: HUM00077717).
Image Acquisition. The scans used in this study were selected from those taken from a previous clinical trial (ID: HUM00026657). ${ }^{11}$ All images were acquired with a CBCT machine (i-CAT, Imaging Sciences International, Hatfield, PA, USA) in the Department of Periodontics and Oral Medicine, University of Michigan School of Dentistry, by board certified Oral and Maxillofacial radiologists between 2009 and 2011. The imaging parameters were set at tube voltage of $120 \mathrm{kVp}$, tube current of $18.66 \mathrm{mAs}$, voxel resolution of $0.4 \mathrm{~mm}$, and a field of view of $6 \mathrm{~cm}$ for a scan time of 20 seconds. Data from the scans were saved in the Digital Imaging and Communications in Medicine format and reconstructed with an implant planning software program (InvivoDent, Invivo5, Anatomage, San Jose, CA, USA).

\section{Inclusion Criteria}

The CBCT images were viewed, at a distance of $30 \mathrm{~cm}$, on a 28-inch desktop monitor with a resolution of 1024 $\times 768$ pixels under room lightening. Two examiners (C.G. and F.S.) screened the CBCT images according to the inclusion and exclusion criteria, and selected those that fulfilled the criteria for this study. Scans that were included had preoperative, immediately after implant placement and 6-month postoperative scans, clear images in the maxilla without artifacts, an edentulous ridge as a result of a missing tooth, an adequate residual ridge width for achieving primary implant stability ( $>3.0 \mathrm{~mm}$ and $>3.5 \mathrm{~mm}$ in width for a missing lateral and central incisor, respectively), ${ }^{15}$ an adequate residual $\mathrm{RH}$ of more than $14 \mathrm{~mm}$, and overall normal tooth alignment. The graft material, membrane and implant used were particulated mineralized human allograft $\left(\right.$ Puros $^{\circledR}$, Zimmer Dental Inc., Carlsbad, CA USA), bovine pericardium membrane (CopiOs ${ }^{\circledR}$, Zimmer Dental Inc.), and dental implants (tapered screw vent implant, Zimmer Dental Inc.), respectively. Scans were excluded if they were unclear or incomplete (e.g., due to scattering), outline of the edentulous ridge could not be identified (e.g., recent extraction sockets), and there was buccal wall dehiscence $(>3 \mathrm{~mm})$ and/or fenestration as determined by assessment of the clinical photograph. Any disagreement was resolved after discussion with a third assessor (H-L.C.).

\section{Image Orientation}

The selected scans were reoriented such that the maxilla was symmetrical and the maxillary plane, defined as the 
line connecting the anterior and posterior nasal spine, was parallel to the ground. The maxillary plane served as the reference line. The reference arch ( $80 \mathrm{~mm}$ wide) was drawn at the level of crestal bone in the transverse view, with its center corresponding to the center of the ridge. The re-orientation of the scans allowed for comparison between scans.

\section{Measurements}

Two examiners (C.G. and F.S.) performed all measurements using the measuring tools available in the software (InvivoDent, Invivo5, Anatomage). Using the Kappa test, inter- and intraexaminer agreements were calculated to be 0.83 and 0.89 , respectively. The following measurements were made in the mid-sagittal plane of the edentulous ridge at baseline (T1), immediately after surgery (T2), and 6 months postsurgery (T3) (Figure 1, A and B):

- Ridge width (RW) was the distance between the buccal and palatal bone plates at $3 \mathrm{~mm}, 6 \mathrm{~mm}$, $9 \mathrm{~mm}$, and $12 \mathrm{~mm}$ apical to the crestal bone

- Ridge angulation (RA) was the angle between the midline of the ridge and the reference line, whereby the midline was determined by vertically connecting the middle of horizontal lines at $3 \mathrm{~mm}, 6 \mathrm{~mm}$, $9 \mathrm{~mm}$, and $12 \mathrm{~mm}$ apical to the crest

- $\mathrm{RH}$ was measured from the bone crest to the base of the maxilla at the midline of the ridge

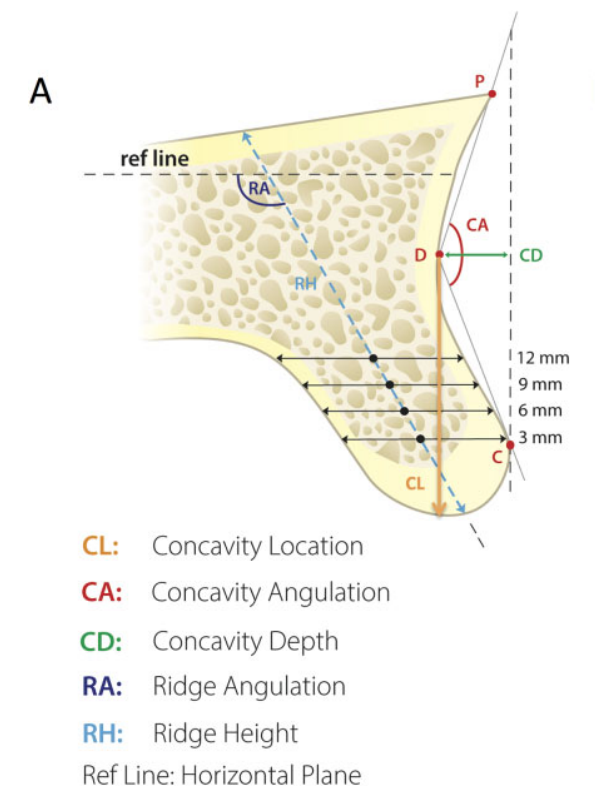

- Concavity depth (CD) was the horizontal distance between the deepest point of the buccal plate (Point $\mathrm{D}$ ) and a vertical reference line perpendicular to the reference line, passing through the most external point of the buccal plate (Point C)

- Concavity angulation (CA) was the angle between line D-C (line connecting points D and $\mathrm{C}$ ) and line $\mathrm{D}-\mathrm{P}$ (line connecting points $\mathrm{D}$ and $\mathrm{P}$ ), whereas point $\mathrm{P}$ was the most external point of the buccal plate coronal to Point D

- Concavity location (CL) was described as the vertical distance between Point D and the alveolar crest.

- Implant angulation (IA): the angle between the maxillary plane and the long axis of the implant

\section{Statistical Analysis}

Descriptive analyses were conducted and expressed as means \pm standard deviations for RW at $3 \mathrm{~mm}, 6 \mathrm{~mm}$, $9 \mathrm{~mm}$, and $12 \mathrm{~mm}$ apical to the crest, RA, CA, and CD. Changes in RW between the three time points, T1, T2, and T3, were calculated. Possible correlations between $\mathrm{RA}, \mathrm{CA}, \mathrm{CD}$, and the final RW gains at various measurement levels were plotted and presented as the square of Pearson's correlation coefficient values $\left(R^{2}\right)$. The Student's $t$-test was used to evaluate the effect of membrane use on RW gains. The significant level was set at 0.05. All analyses were performed with a commercially available

B

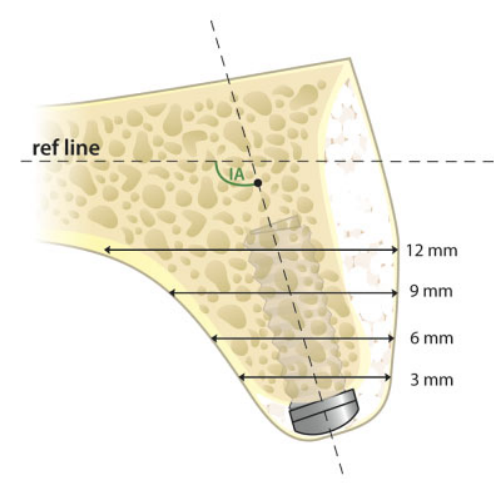

IA: Implant Angulation

Figure 1 Assessment of the ridge morphology. A, Assessment of the ridge morphology at baseline. $B$, Assessment of the ridge morphology after bone augmentation with the SBA technique. 


\begin{tabular}{|c|c|c|c|c|c|}
\hline \multirow[b]{2}{*}{ Intervals } & \multicolumn{4}{|c|}{ Mean RW (Standard Deviation) (mm) } & \multirow{2}{*}{$\begin{array}{c}\text { Mean RA (Standaro } \\
\text { Deviation) }\left({ }^{\circ}\right)\end{array}$} \\
\hline & $3 \mathrm{~mm}$ & $6 \mathrm{~mm}$ & $9 \mathrm{~mm}$ & $12 \mathrm{~mm}$ & \\
\hline $\mathrm{T} 1$ & $6.73(1.38)$ & $7.99(2.20)$ & $9.48(3.27)$ & $10.97(5.42)$ & $119.05(10.03)$ \\
\hline $\mathrm{T} 2$ & $9.76(1.48)$ & $12.49(2.02)$ & $14.42(2.52)$ & $15.80(4.08)$ & $110.83(10.43)$ \\
\hline $\mathrm{T} 3$ & $8.32(1.30)$ & $10.54(2.37)$ & $12.18(3.11)$ & $13.49(4.59)$ & $115.64(9.63)$ \\
\hline
\end{tabular}

$\mathrm{RA}=$ ridge angulation; $\mathrm{RW}=$ ridge width; $\mathrm{T} 1=$ baseline; $\mathrm{T} 2=$ immediately after surgery; $\mathrm{T} 3=6$ months after surgery.

\section{TABLE 2 Changes in Ridge Width at Different Time Intervals}

\begin{tabular}{|c|c|c|c|c|c|}
\hline \multirow[b]{2}{*}{ Intervals } & \multicolumn{5}{|c|}{ Changes in RW (Standard Deviation) (mm) } \\
\hline & $3 \mathrm{~mm}$ & $6 \mathrm{~mm}$ & $9 \mathrm{~mm}$ & $12 \mathrm{~mm}$ & Average \\
\hline T1-T2 (RW Gain) & $3.04(1.76)$ & $4.50(1.65)$ & $4.94(1.89)$ & $4.83(2.55)$ & $4.33(1.96)$ \\
\hline T2-T3 (RW Loss) & $1.43(1.10)$ & $1.95(1.56)$ & $2.24(1.72)$ & $2.50(1.85)$ & $2.02(1.56)$ \\
\hline T1-T3 (RW Gain) & $1.65(1.53)$ & $2.56(2.23)$ & $2.72(2.45)$ & $2.29(2.61)$ & $2.30(2.20)$ \\
\hline
\end{tabular}

$\mathrm{RW}=$ ridge width; $\mathrm{T} 1$ = baseline; $\mathrm{T} 2=$ immediately after surgery; $\mathrm{T} 3=6$ months after surgery .

software program (Excel 2012, Microsoft ${ }^{\circledR}$, Redmond WA, USA).

\section{RESULTS}

Seventy-eight scans from 26 subjects ( 13 males and 13 females) were available for this study. The mean patient age was $48.6 \pm 8.8$ years (range of 31-64 years). Twentyone scans from seven subjects were excluded because scattering artifacts obscured the images. A total of 57 scans from 19 subjects were thus included in this study.

Table 1 showed the overall changes in ridge morphology at baseline, immediately after surgery and 6 months postsurgery. At baseline, the mean RW at $3 \mathrm{~mm}$, $6 \mathrm{~mm}, 9 \mathrm{~mm}$, and $12 \mathrm{~mm}$ was $6.73(1.38) \mathrm{mm}, 7.99$ (2.20) mm, $9.48(3.27) \mathrm{mm}$, and $10.97(5.42) \mathrm{mm}$, respectively. In addition, the mean RA was 119.05 $(10.03)^{\circ}$. The mean CD, CA, and CL were 4.39 (2.65) $\mathrm{mm}, 146.32(13.27)^{\circ}$, and $12.31(4.24) \mathrm{mm}$, respectively. Immediately after surgery, a significant increase in RW was evident and expected. The mean RW at $3 \mathrm{~mm}$, $6 \mathrm{~mm}, 9 \mathrm{~mm}$, and $12 \mathrm{~mm}$ was $9.76(1.48) \mathrm{mm}, 12.49$ (2.02) $\mathrm{mm}, 14.42(2.52) \mathrm{mm}$, and $15.80(4.08) \mathrm{mm}$, respectively. In addition, the mean RA and IA within this group were $110.83(10.43)^{\circ}$ and $102.10(9.26)^{\circ}$. At the 6-month postsurgery review, the mean RW at $3 \mathrm{~mm}$, $6 \mathrm{~mm}, 9 \mathrm{~mm}$, and $12 \mathrm{~mm}$ was $8.32(1.30) \mathrm{mm}, 10.54$ (2.37) mm, 12.18 (3.11) mm, and 13.49 (4.59) mm, with a mean RA of $115.64(9.63)^{\circ}$. The interval between T2 and T3 was 6.09 (0.29) months. The comparisons of changes in ridge morphology at all measurement locations showed an overall mean RW gain of 2.30 (2.20) $\mathrm{mm}$ obtained after GBR, with the SBA technique at 6 months (Figure 2 and Table 2).

Furthermore, statistically significant difference $(p<.05)$ in mean RW gain was found between the membrane and no membrane groups. At $6 \mathrm{~mm}$ and $9 \mathrm{~mm}$ apical to the crest, the mean bone loss between T2-T3 was 2.89 (1.22) $\mathrm{mm}$ in the group that received a barrier membrane. However, the mean bone loss between

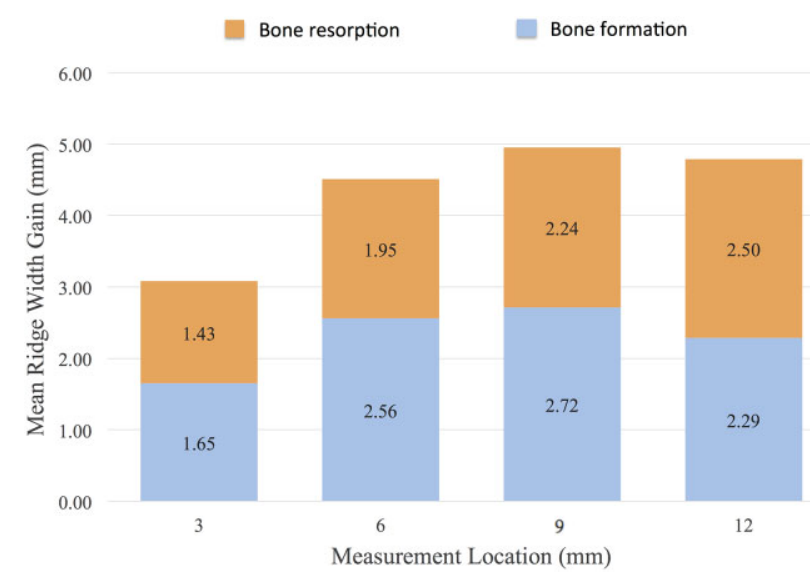

Figure 2 Mean ridge width gain at all measurement locations. 


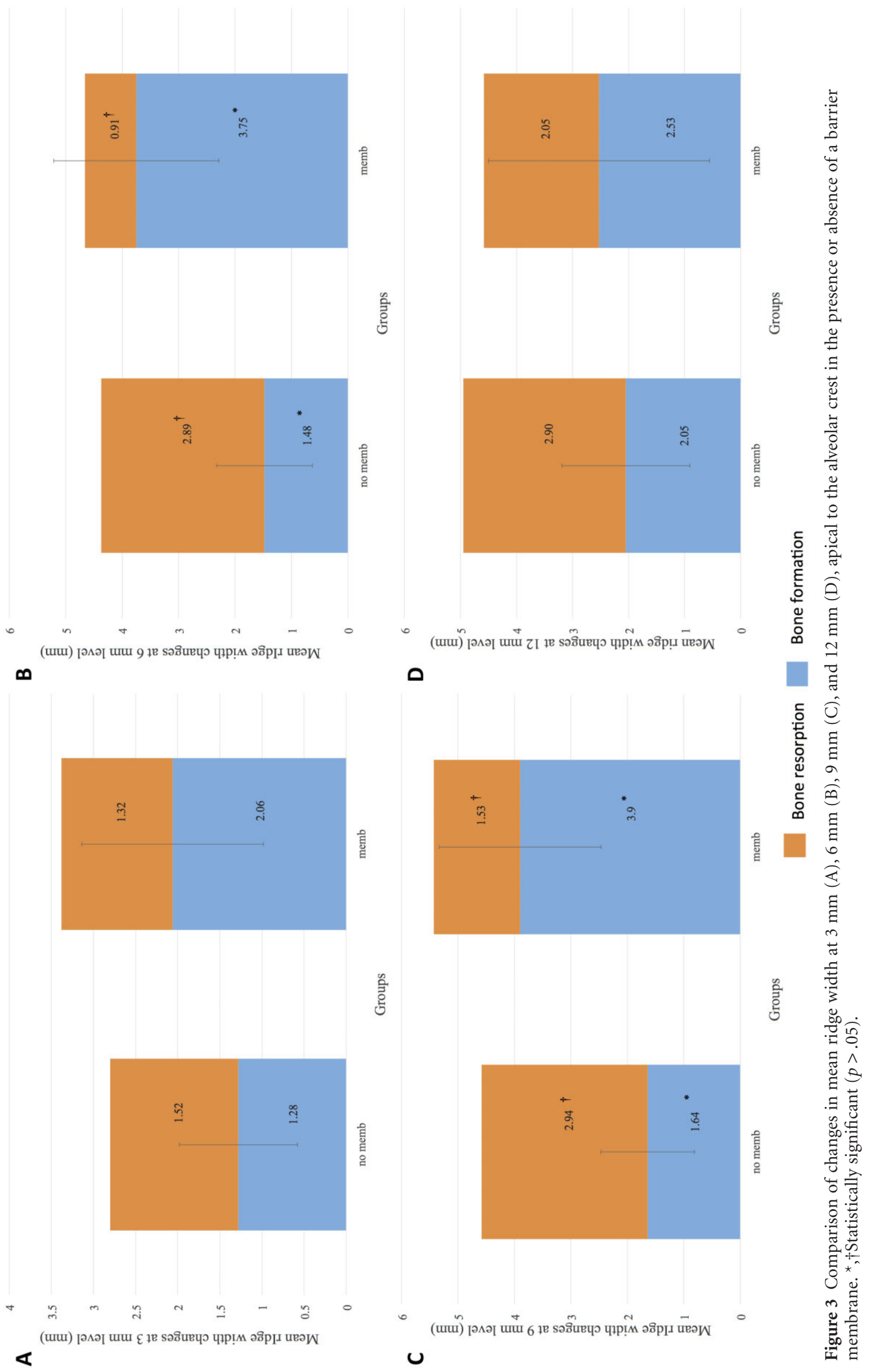



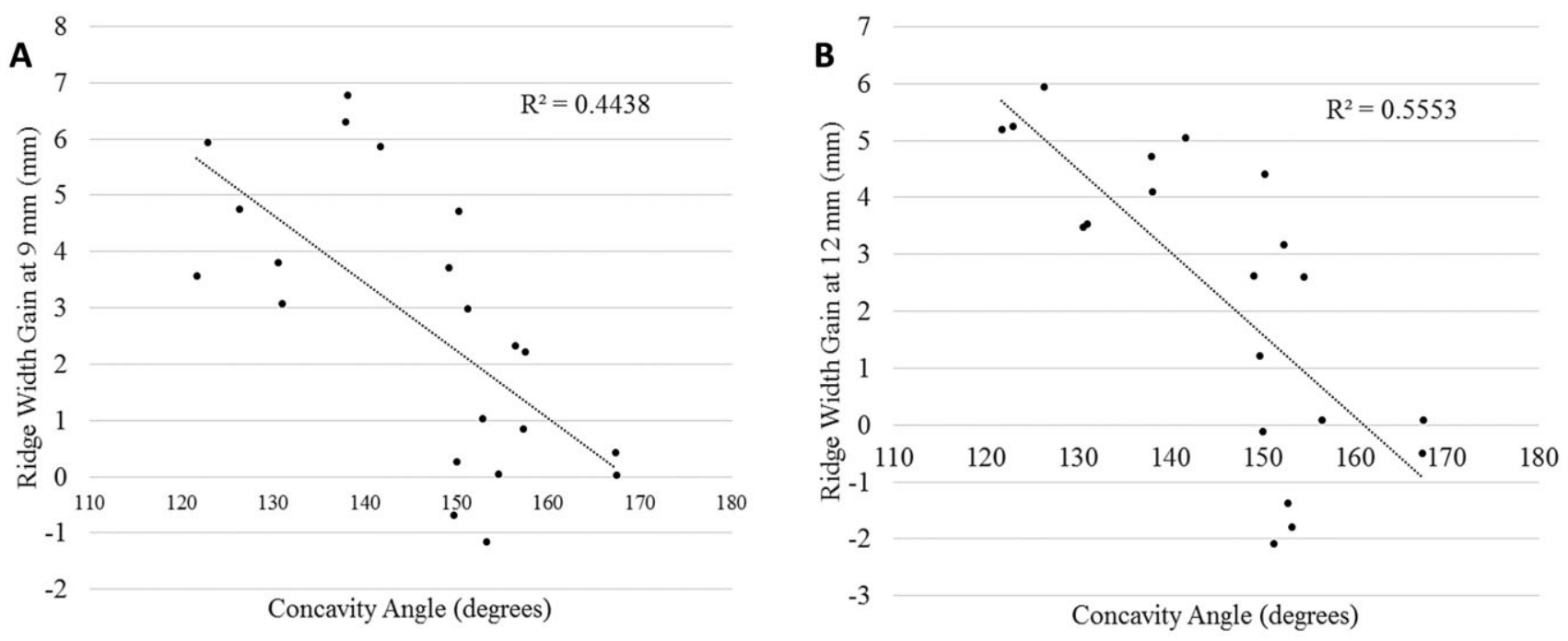

Figure 4 The effect of concavity angulation on mean ridge width gain at (A) $9 \mathrm{~mm}$ and (B) $12 \mathrm{~mm}$ apical to bone crest.

T2-T3 was $2.94(1.22) \mathrm{mm}$ in the group that did not receive a barrier membrane. The mean bone loss at $6 \mathrm{~mm}$ and $9 \mathrm{~mm}$ apical to the crest was $0.91(1.20) \mathrm{mm}$ and $1.53(1.20) \mathrm{mm}$, respectively, in the membrane group, as compared with 2.89 (1.22) $\mathrm{mm}$ and 2.94 (1.22) $\mathrm{mm}$, respectively in the no membrane group (Figure 3 ). Moreover, an overall mean bone gain in the membrane group was $3.75(2.36) \mathrm{mm}$ and $3.90(2.67) \mathrm{mm}$, respectively, at $6 \mathrm{~mm}$ and $9 \mathrm{~mm}$ apical to the crest, as compared with 1.48 (1.50) and $1.64(1.69) \mathrm{mm}$ in the no membrane group (Figure 3).

It could be concluded that the higher the CA, the lesser the RW gain (Figure 4). However, the effect of CA on mean RW gain was only significant at $9 \mathrm{~mm}$ and $12 \mathrm{~mm}$ apical to the crest. Interestingly, at $9 \mathrm{~mm}$ apical to the crest, a critical CA of $150^{\circ}$ was found. If the CA was less than $150^{\circ}$, the mean bone gain was 4.3 (2.2) $\mathrm{mm}$. Conversely, if the CA was more than $150^{\circ}$, the mean bone gain was $1.3(1.7) \mathrm{mm}(p=.001)$.

\section{DISCUSSION}

This study aimed to evaluate the effect of ridge morphology on the amount of horizontal bone augmentation achievable with the SBA technique and simultaneous implant placement. As proven by this study, the SBA is a predictable GBR technique, based on the mean amount of horizontal ridge width gain. All implants placed achieved horizontal bone gain after 6 months, regardless of the implant location, ridge morphology, and use of membranes.

Lower mean ridge width gain was observed at $3 \mathrm{~mm}$ and $12 \mathrm{~mm}$ apical to crest. It was speculated that the reduction in bone gain was due to higher soft tissue pressure in these areas. However, there was greater mean ridge width gain at $6 \mathrm{~mm}$ and $9 \mathrm{~mm}$ apical to crest. This could be attributed to a more favorable defect morphology at these sites, as expressed by the concavity angle. The more acute the concavity angle, the deeper the defect, thus allowing the barrier membrane to better create and maintain the space for bone regeneration. This was in concordance with a recent study that reported greater dehiscence defect reduction when the ridge angle is less than $28^{\circ} .{ }^{14}$ In addition, previous studies on guided tissue regeneration, also demonstrated that the more contained the defect, the better the regenerative outcome. ${ }^{16,17}$ This is because there is better tenting of the barrier membrane for space maintenance purposes. As such, there is a smaller risk of the barrier membrane collapsing into the defect, resulting in lesser amount of bone regeneration.

Our results also showed that the use of barrier membranes prevented significant bone resorption during the healing period, and thus greater mean ridge width gain was obtained. This was achievable because the barrier membrane excluded undesirable cells, for example, epithelial and connective tissue cells from populating the wound site, therefore allowing cells with regenerative potential, for example, osteoblasts to colonize the defect and form bone. ${ }^{5}$ In this study, a bovine pericardium membrane $\left(\mathrm{CopiOs}^{\circledR}\right.$ pericardium membrane, Zimmer Dental Inc.) was used as the barrier membrane for horizontal bone augmentation. It is processed in a unique manner (Tutoplast ${ }^{\circledR}$; RTI Biologics Inc., Alachua, FL, USA) that allows the membrane to 
retain its original structure; therefore, no membrane is the same as the other. However, this membrane is soft and drapes over the defect. In wider defects, it is speculated that there is lesser bone regeneration because of the collapse of the membrane into the defect.

Despite the limitations of this study, which were the small sample size and short study period, the SBA technique demonstrated success in gaining ridge width with simultaneous implant placement. It enjoyed good success ${ }^{9,11,12,18}$ because it utilized particulated cancellous and cortical allografts together with a collagen membrane to simulate the composition of native bone. In addition, significantly greater horizontal bone gain was achieved in the presence of barrier membranes and in ridges with more acute concavity angles.

\section{CONCLUSION}

Within the limitations of the present study, the SBA technique is a predictable method for gaining horizontal ridge width in the maxilla. The use of barrier membranes and concavity angulation appeared to affect the amount of bone regeneration achieved by GBR.

\section{ACKNOWLEDGMENTS}

This study was partially supported by the University of Michigan Periodontal Graduate Student Research Fund. The authors would like to acknowledge Ms. Claire Jones for the design of the illustrations in this manuscript. The authors report no conflicts of interest related to this study.

\section{REFERENCES}

1. Schropp L, Wenzel A, Kostopoulos L, Karring T. Bone healing and soft tissue contour changes following singletooth extraction: a clinical and radiographic 12-month prospective study. Int J Periodontics Restorative Dent 2003; 23:313-323.

2. Araujo MG, Lindhe J. Dimensional ridge alterations following tooth extraction. An experimental study in the dog. J Clin Periodontol 2005; 32:212-218.

3. Buser D, Dula K, Belser U, Hirt HP, Berthold H. Localized ridge augmentation using guided bone regeneration. 1 . Surgical procedure in the maxilla. Int J Periodontics Restorative Dent 1993; 13:29-45.
4. Buser D, Dula K, Belser UC, Hirt HP, Berthold H. Localized ridge augmentation using guided bone regeneration. II. Surgical procedure in the mandible. Int J Periodontics Restorative Dent 1995; 15:10-29.

5. Melcher AH. On the repair potential of periodontal tissues. J Periodontol 1976; 47:256-260.

6. Dahlin C, Linde A, Gottlow J, Nyman S. Healing of bone defects by guided tissue regeneration. Plast Reconstr Surg 1988; 81:672-676.

7. Fiorellini JP, Nevins ML. Localized ridge augmentation/ preservation. A systematic review. Ann Periodontol 2003; 8:321-327.

8. Amorfini L, Migliorati M, Signori A, Silvestrini-Biavati A, Benedicenti S. Block allograft technique versus standard guided bone regeneration: a randomized clinical trial. Clin Implant Dent Relat Res 2013 [Epub ahead of print].

9. Wang HL, Misch C, Neiva RF. "Sandwich" bone augmentation technique: rationale and report of pilot cases. Int J Periodontics Restorative Dent 2004; 24:232-245.

10. Lee A, Brown D, Wang HL. Sandwich bone augmentation for predictable horizontal bone augmentation. Implant Dent 2009; 18:282-290.

11. Fu JH, Oh TJ, Benavides E, Rudek I, Wang HL. A randomized clinical trial evaluating the efficacy of the sandwich bone augmentation technique in increasing buccal bone thickness during implant placement surgery: I. Clinical and radiographic parameters. Clin Oral Implants Res 2013 [Epub ahead of print].

12. Park SH, Lee KW, Oh TJ, et al. Effect of absorbable membranes on sandwich bone augmentation. Clin Oral Implants Res 2008; 19:32-41.

13. Wang HL, Boyapati L. "PASS" principles for predictable bone regeneration. Implant Dent 2006; 15:8-17.

14. Park SH, Brooks SL, Oh TJ, Wang HL. Effect of ridge morphology on guided bone regeneration outcome: conventional tomographic study. J Periodontol 2009; 80: 1231-1236.

15. Fu JH, Wang HL. Horizontal bone augmentation: the decision tree. Int J Periodontics Restorative Dent 2011; 31: 429-436.

16. Tonetti MS, Pini-Prato G, Cortellini P. Periodontal regeneration of human intrabony defects. IV. Determinants of healing response. J Periodontol 1993; 64:934-940.

17. Becker W, Becker BE, Berg L, Samsam C. Clinical and volumetric analysis of three-wall intrabony defects following open flap debridement. J Periodontol 1986; 57:277-285.

18. Oh TJ, Meraw SJ, Lee EJ, Giannobile WV, Wang HL. Comparative analysis of collagen membranes for the treatment of implant dehiscence defects. Clin Oral Implants Res 2003; 14:80-90. 